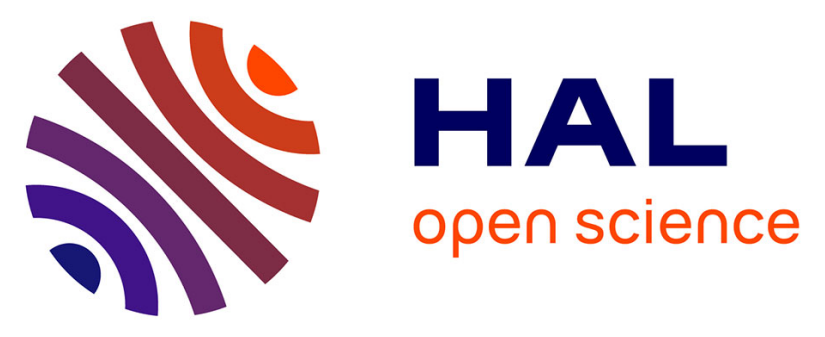

\title{
Adaptive SLAM with synthetic stereo dataset generation for real-time dense $3 \mathrm{D}$ reconstruction
}

Sébastien Pouteau, Antoine Billy, Pascal Desbarats, Serge Chaumette

\section{To cite this version:}

Sébastien Pouteau, Antoine Billy, Pascal Desbarats, Serge Chaumette. Adaptive SLAM with synthetic stereo dataset generation for real-time dense 3D reconstruction. 5th International Workshop - Unmanned and Swarming Conference Research Challenges for Future Unmanned Systems and Autonomous Swarming, Oct 2018, Mérignac, France. hal-01900356

\section{HAL Id: hal-01900356 https://hal.science/hal-01900356}

Submitted on 22 Oct 2018

HAL is a multi-disciplinary open access archive for the deposit and dissemination of scientific research documents, whether they are published or not. The documents may come from teaching and research institutions in France or abroad, or from public or private research centers.
L'archive ouverte pluridisciplinaire HAL, est destinée au dépôt et à la diffusion de documents scientifiques de niveau recherche, publiés ou non, émanant des établissements d'enseignement et de recherche français ou étrangers, des laboratoires publics ou privés. 


\title{
Adaptive SLAM with synthetic stereo dataset generation for real-time dense 3D reconstruction
}

\author{
Sébastien POUTEAU, Antoine BILLY, Pascal DESBARATS, Serge CHAUMETTE \\ Laboratoire Bordelais de Recherche en Informatique (LaBRI), Talence, France
}

\section{Abstract}

In robotic mapping and navigation, of prime importance today with the trend for autonomous cars, simultaneous localization and mapping (SLAM) algorithms often use stereo vision to extract 3D information of the surrounding world. Whereas the number of creative methods for stereo-based SLAM is continuously increasing, the variety of datasets is relatively poor and the size of their contents relatively small. This size issue is increasingly problematic, with the recent explosion of deep learning based approaches, several methods require an important amount of data. Those multiple techniques contribute to enhance the precision of both localization estimation and mapping estimation to a point where the accuracy of the used sensors to get the ground truth might be questioned. Finally, because today most of these technologies are embedded on on-board systems, the power consumption and real-time constraints turn to be key requirements. Our contribution is twofold: we propose an adaptive SLAM method that reduces the number of processed frame with minimum impact error, and we make available a synthetic flexible stereo dataset with absolute ground truth, which allows to run new benchmarks for visual odometry challenges. This dataset is available online.

\section{Adaptative SLAM Algorithm}
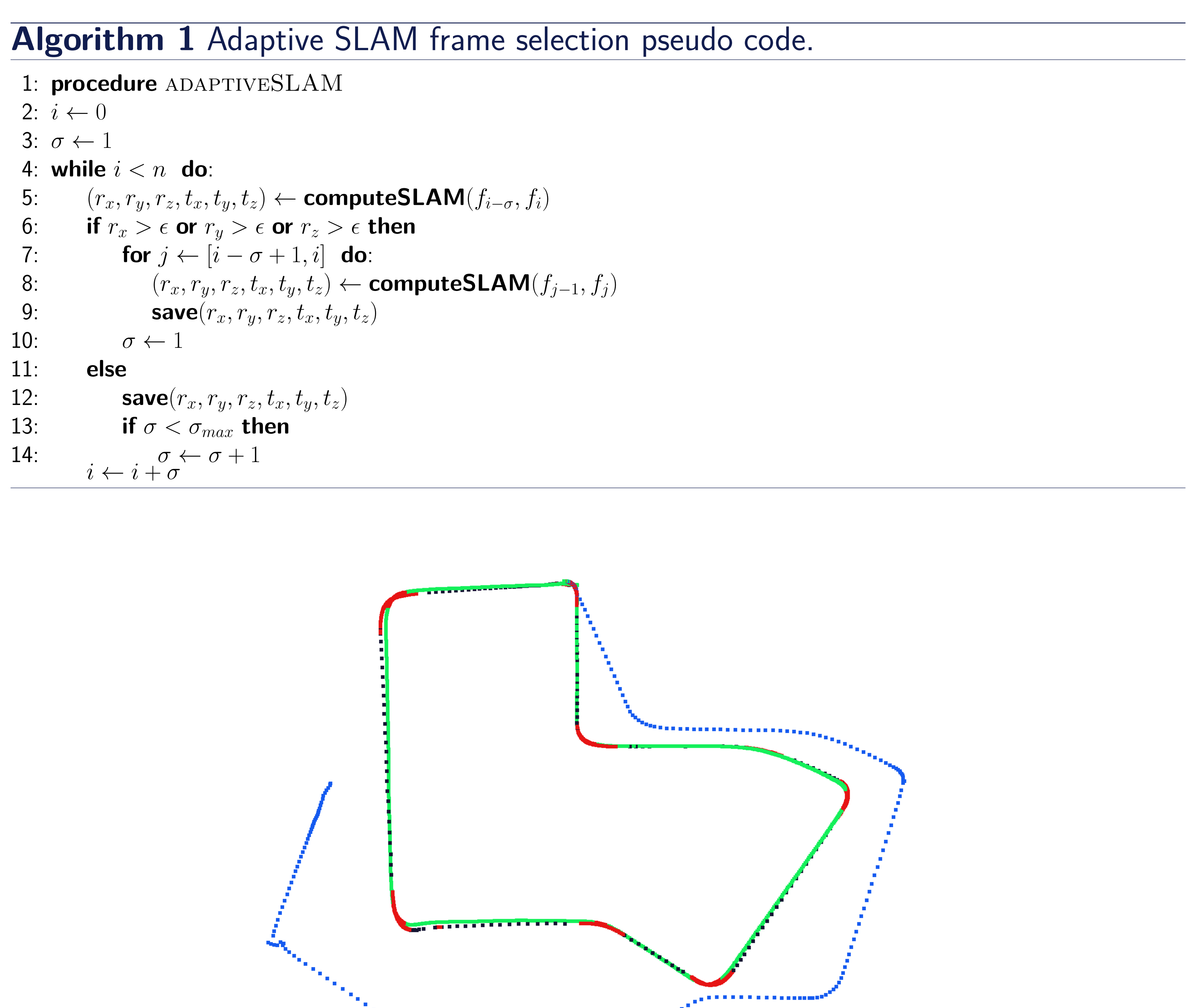

Figure 1: Illustration of Adaptive SLAM frame selection. This figure illustrates in blue what would happen if we keep the reduced frame rate for the entire sequence. The trajectories strongly spreads off the ground truth (green dots), whereas the adaptive SLAM remains very close to it.

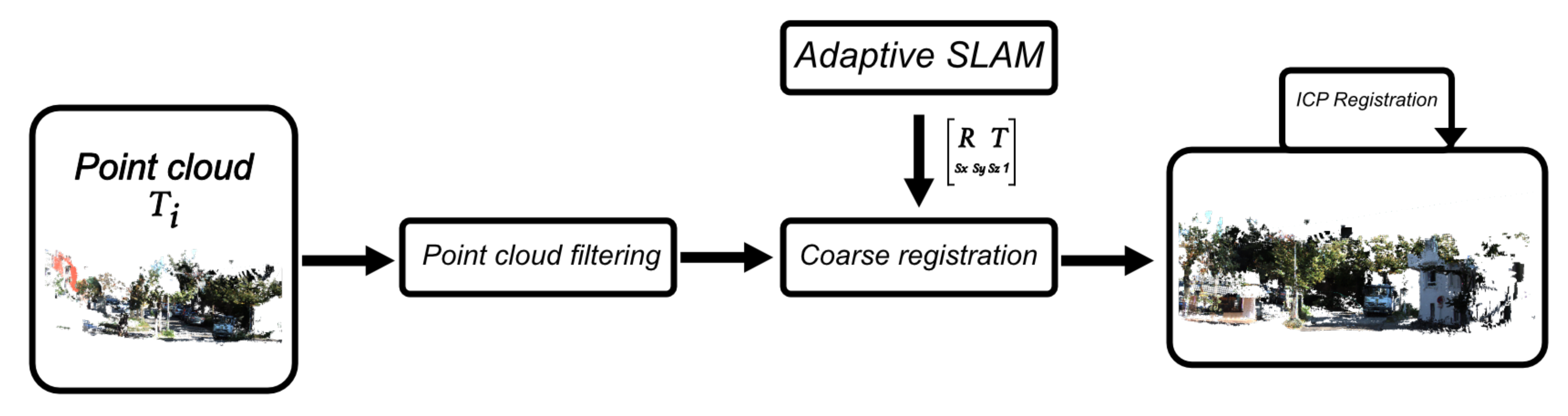

Figure 2: Pipeline of global 3D dense reconstruction using adaptive SLAM algorithm. Two fully reconstructed point clouds are shown in figure 5

\section{Conclusion}

We presented an optimization of SLAM algorithm that reduces the number of processed frames without increasing the generated error. We showed that this method significantly increases performances for real-time scenarios, and is applicable on well known datasets. We used our method inside a 3D dense reconstruction pipeline and demonstrated that the results were perfectly suitable for dense reconstruction. Secondly, aiming at proving our concept and answering the needs of requested stereo dataset for SLAM estimation, we made available, to our knowledge, the first synthetic stereo dataset for SLAM applications: Alastor. Our experiments showed that adaptive SLAM performs great on simulated data. We hope that our dataset will lead to innovative methods that will take advantage of the tunable parameters in order to improve the effectiveness of SLAM solving algorithms in the future.

\section{Contact Information}

\section{Alastor Dataset}

We made available the first synthetic stereo dataset for visual SLAM. This dataset contains several acquisitions within multiples categories (straight lines, rotations, rainy weather, night scenes) that are downlodable witht their corresponding ground truth and LiDAR acquisition. Check it at http://alastor.labri.fr/.

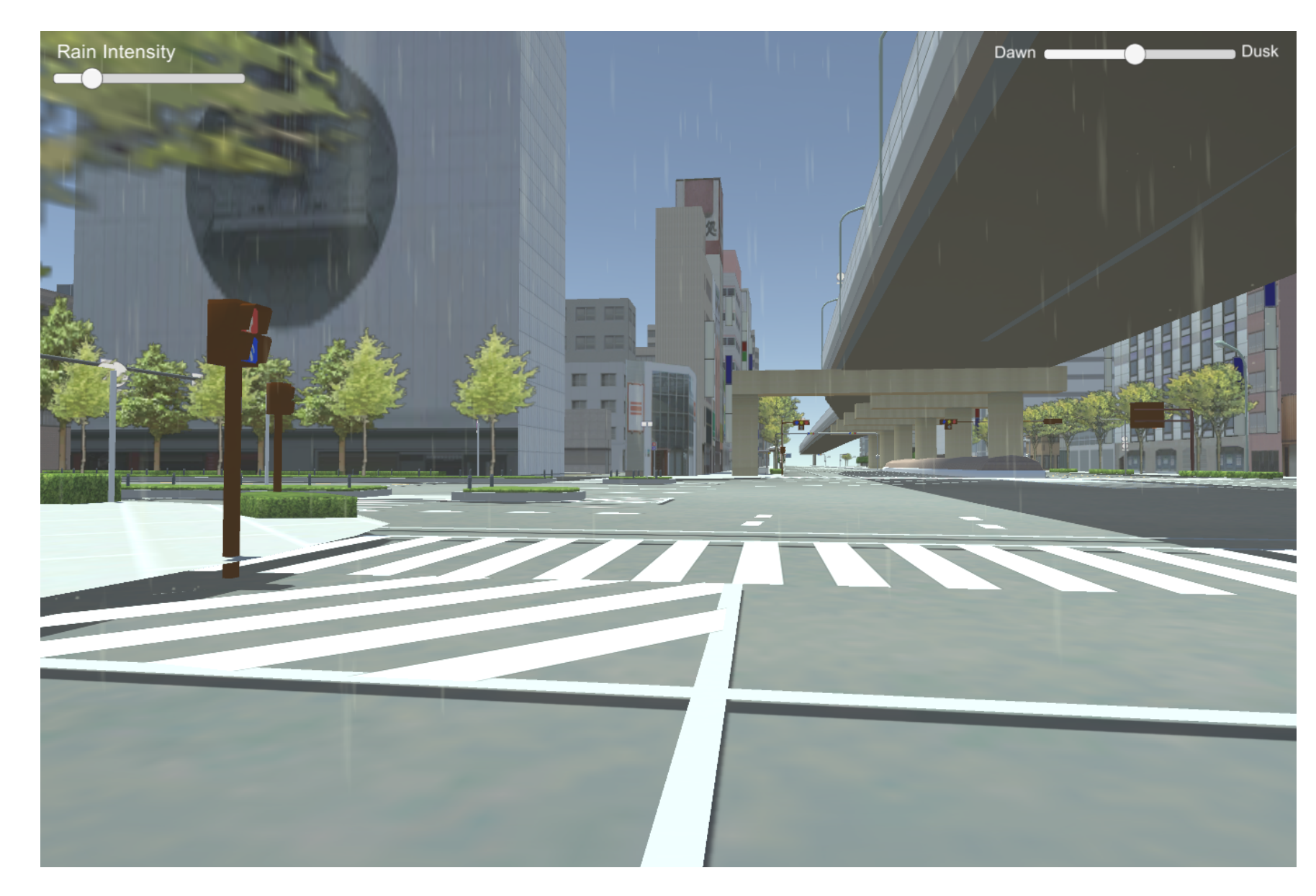

(a)

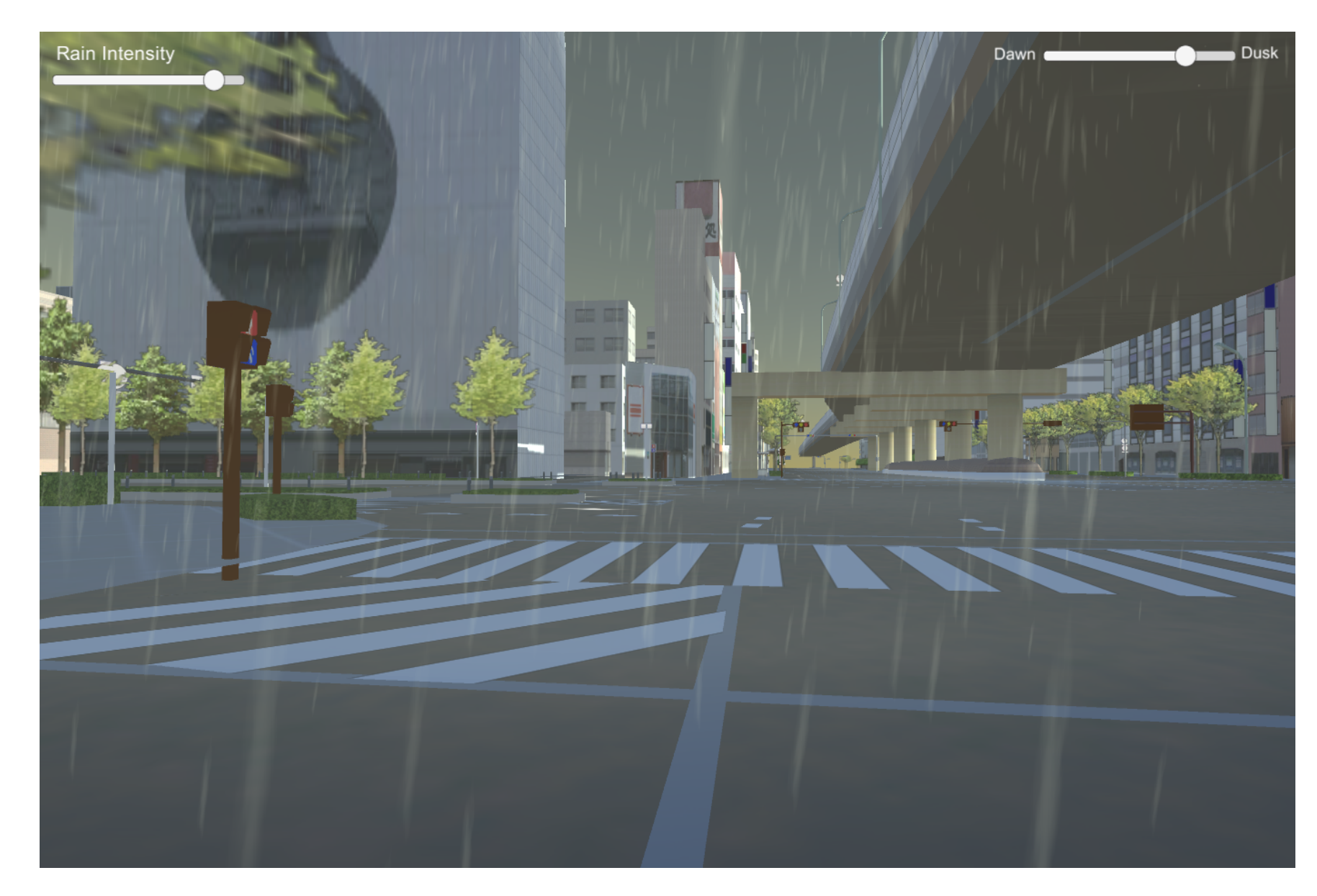

(b)
Figure 3: Alastor simulation engine outputs. With different weather and lighting conditions: (a) Simulation during daylight with light rain, (b) during dawn with strong rain.

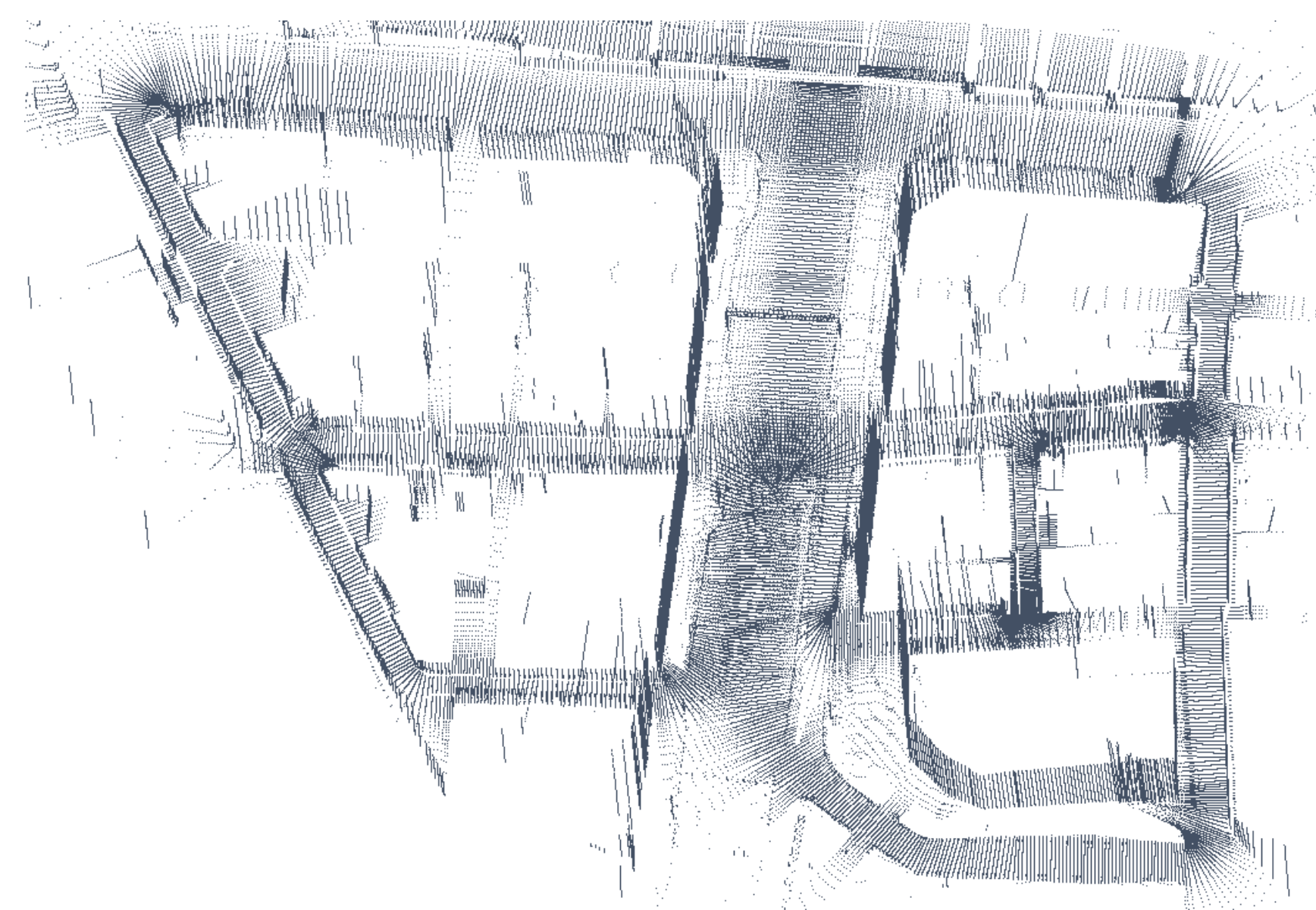

Figure 4: Example of LiDAR simulation acquisition included in the downlodable dataset.

Results

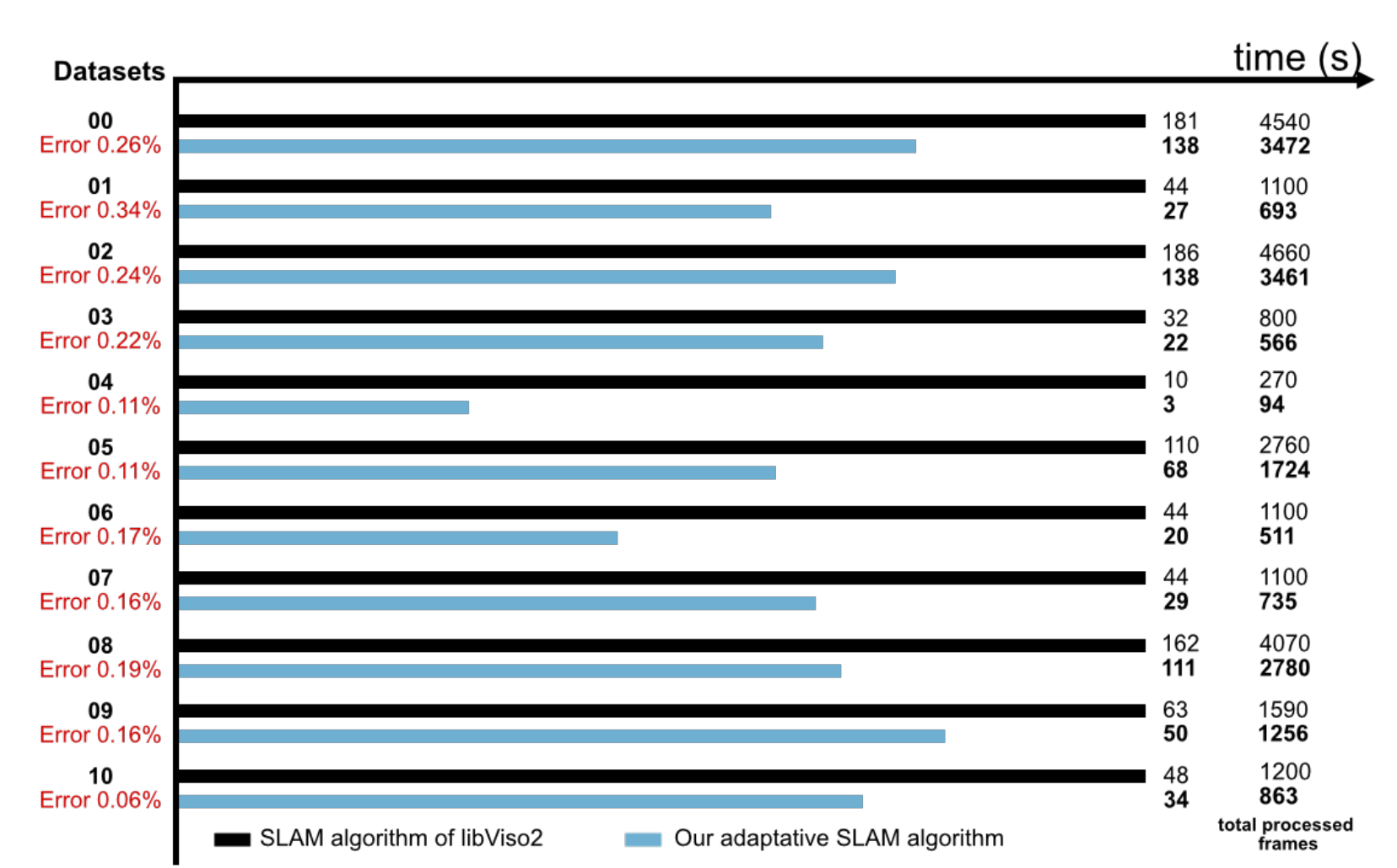

(a)

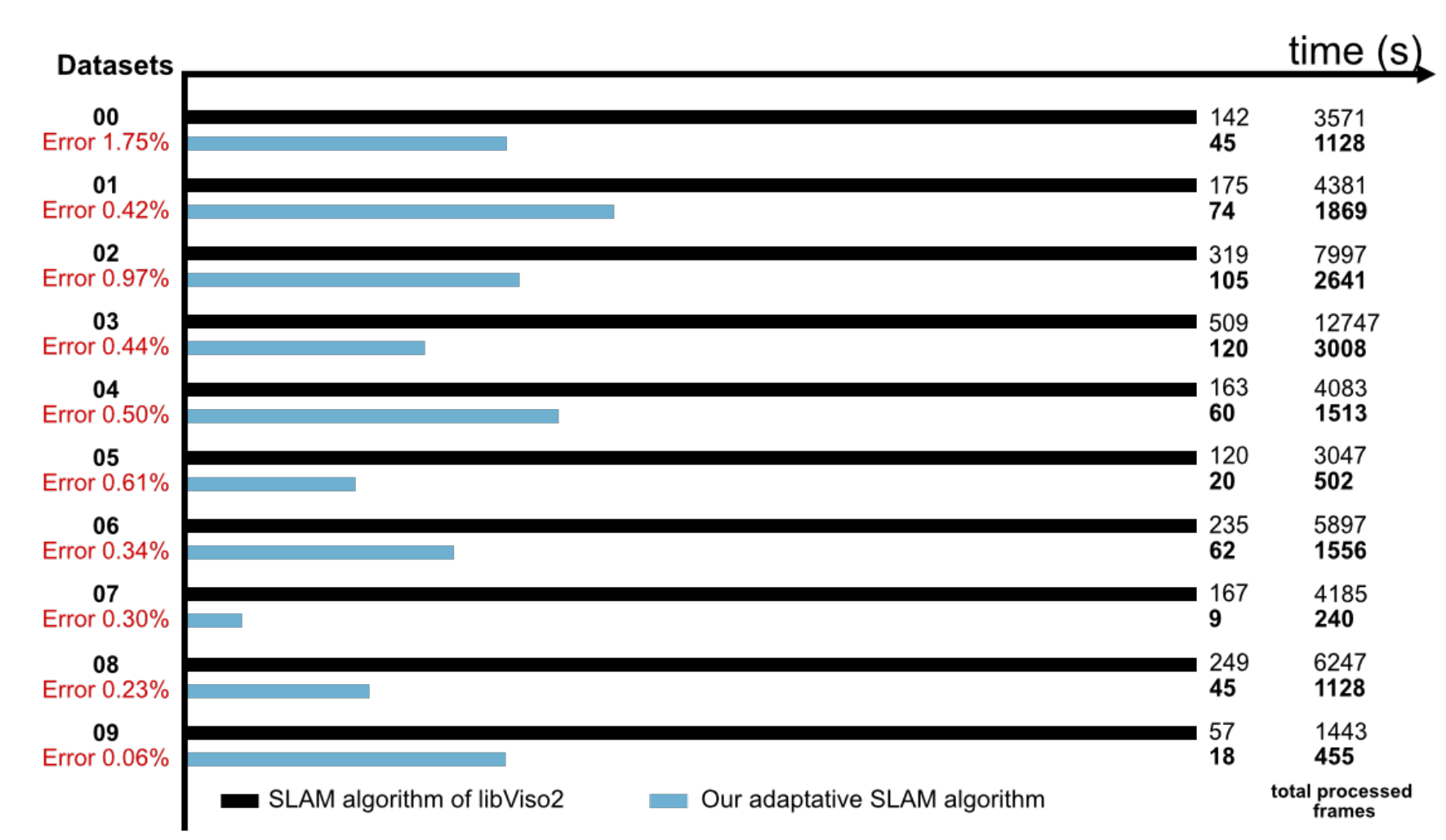

(b)
Figure 5: Evaluation of adaptive SLAM algorithm compared to libviso2: (a) on the KITTI dataset, (b) on Alastor dataset. Those diagrams show that we efficiently reduce the number of processed frame without increasing the overall error.

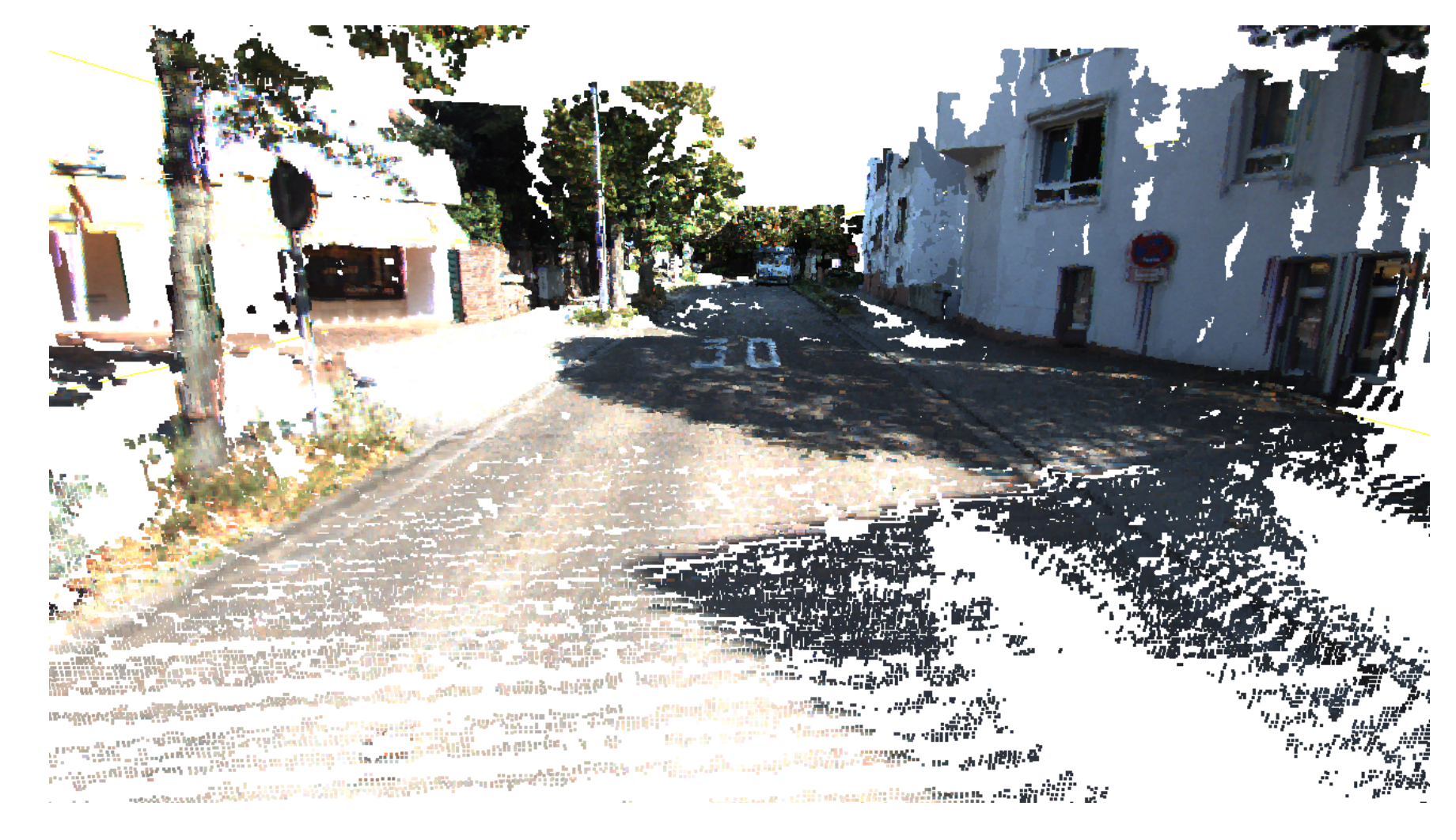

(a)

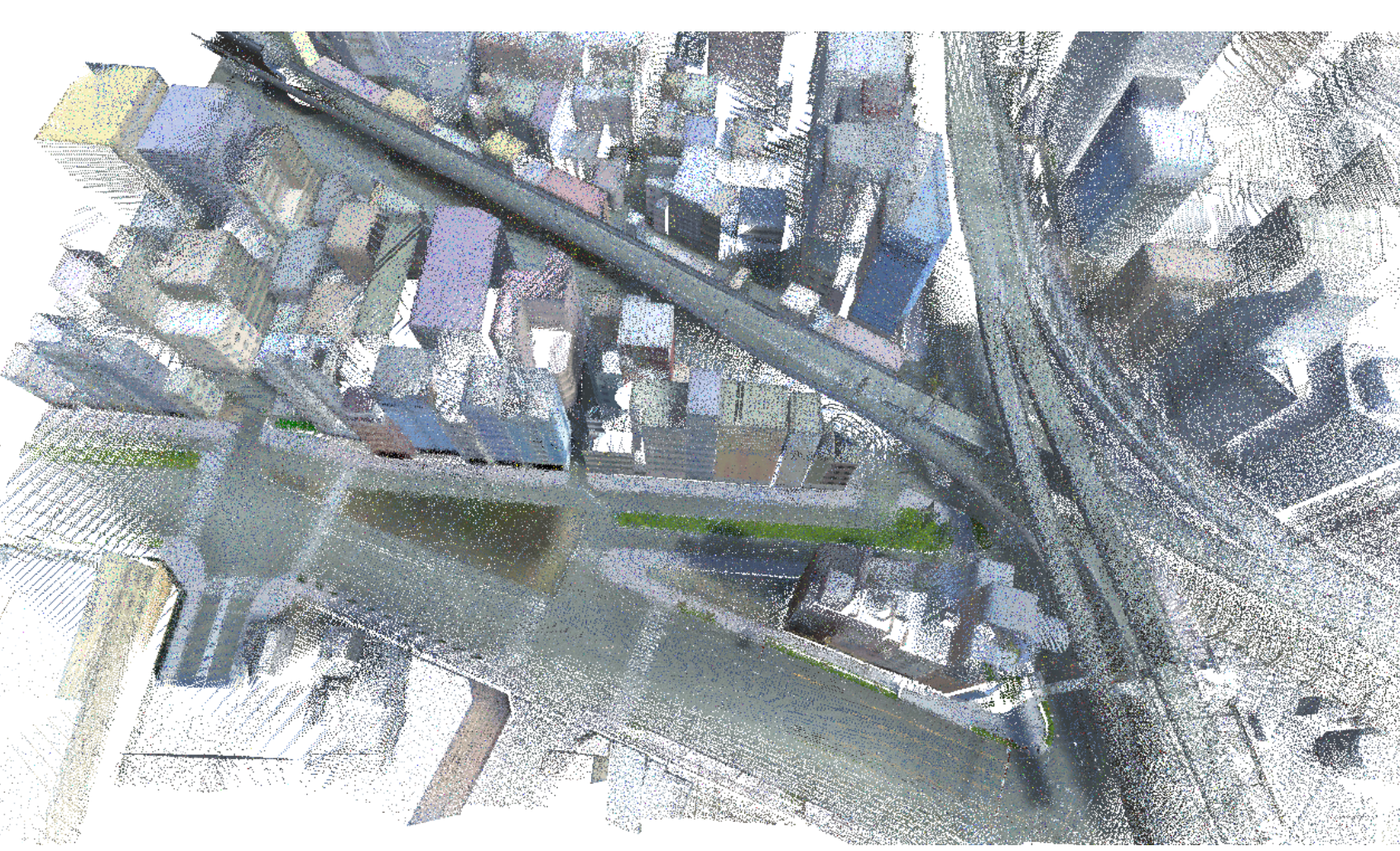

(b)
Figure 6: (a) 3D dense reconstruction of KITTI dataset. (b) 3D dense reconstruction of Alastor dataset. Main References

A. Geiger, P. Lenz, and R. Urtasun. Are we ready for autonomous driving? the kitti vision benchmark suite. In Computer Vision and Pattern Recognition (CVPR), 2012 IEEE Conference on, pages 3354-3361. IEEE, 2012. 2] A. Howard. Real-time stereo visual odometry for autonomous ground vehicles. In Intelligent Robots and Systems, 2008. IROS 2008. IEEE/RSJ International Conference on, pages 3946-3952. IEEE, 2008 